\title{
Foot drop with a popliteal artery aneurysm due to heroin use: A case report
}

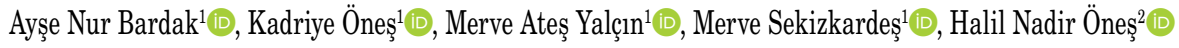 \\ 'Department of Physical Medicine and Rehabilitation, $70^{\text {th }}$ Year Physical Therapy and Rehabilitation Center, İstanbul, Turkey \\ ${ }^{2}$ Department of Orthopedics and Traumatology, Bakırköy Dr. Sadi Konuk Training and Research Hospital, İstanbul, Turkey \\ Received: September 13, 2017 Accepted: November 08, 2017 Published online: July 28, 2018
}

\begin{abstract}
Drug addiction has become an important problem worldwide, and the number of heroin users has been rapidly increasing. There are serious complications related to intravenous drug use. Sharing injectors and using them multiple times cause septic and infective complications. Another important aspect of intravenous drug use is that it potentiates vascular damage. Contaminated injectors may induce pseudoaneurysms when applied directly into the vessel, endothelium, or surrounding tissues. Infected pseudoaneurysms may provoke necrosis, rupture, bleeding, and some dramatic results such as loss of extremity or death. Herein, we report a female case who had a history of long-term substance abuse in whom foot drop developed with a popliteal artery aneurysm.
\end{abstract}

Keywords: Heroin; intravenous drug; popliteal artery; pseudoaneurysm.

Drug addiction has become a critical problem worldwide, particularly in the past two decades. Abuse of substances such as heroin, cocaine, and amphetamine causes serious social and health problems. It is estimated that there are approximately 13.2 million individuals in the world who use intravenous (IV) drugs. ${ }^{[1]}$ A study conducted in the United States of America showed that ratio of heroin users was $0.3 \%$ between 2001 and 2002, and it increased up to $1.6 \%$ between 2012 and 2013. As the number of substance users increases, the frequency of complications due to substance abuse also increases $(0.21 \%$ and $0.69 \%){ }^{[2]}$ Heroin use has a damaging effect on brain functions, and this effect tends to increase in prolonged use. Consequently, the individual becomes impulsive and makes unhealthy decisions. ${ }^{[3]}$ The use of injections increases the risk of bacterial skin and soft tissue infections, abscess formation, phlebitis, endocarditis, and osteomyelitis and it also escalates the risk of hepatitis $\mathrm{C}$ virus (HCV) and human immunodeficiency virus (HIV) infections. ${ }^{[4-8]}$

Another important complication due to IV drug use is that it potentiates vascular damage. ${ }^{[9]}$ Sharing injectors, using them multiple times, and misuse cause septic and infective complications. Contaminated injectors induce pseudoaneurysms when applied directly into the vessel, endothelium, or surrounding tissues. Infected pseudoaneurysms may provoke necrosis, rupture, bleeding, and some dramatic results such as loss of extremity or death. ${ }^{[9]}$ Addicts usually prefer femoral area due to easy access and injection. Pseudoaneurysms due to substance use are typically seen in the femoral artery; however, in the upper extremity, pseudoaneurysms are usually seen in the brachial artery. ${ }^{[9,10]}$ Herein, we report a female case who had a history of long-term substance abuse in whom foot drop developed with a popliteal artery aneurysm.

\section{CASE REPORT}

A 37-year-old female patient was admitted to our outpatient clinic with left lower extremity weakness, pain, and difficulty in walking one year ago. The patient who had an IV substance abuse history of 22 years was admitted to emergency unit two years ago due to blood overflow after IV injection in the popliteal artery. Lower extremity arterial Doppler ultrasound showed a popliteal artery pseudoaneurysm

Corresponding author: Ayşe Nur Bardak, MD. 70. Yll Fizik Tedavi ve Rehabilitasyon Merkezi, Fiziksel Tıp ve Rehabilitasyon Kliniği, 34186 Bahçelievler, İstanbul, Turkey. e-mail: abardak7@gmail.com 
which was operated. The pseudoaneurysm capsule was opened and hematoma was drained via popliteal fossa. Then, the popliteal artery was clamped and a vena saphena magna graft was used. A vacuum-assisted closure device was applied to the popliteal area in the postoperative period due to inflammatory fluid collection in the popliteal fossa. Protective fasciotomy was also performed. The patient was admitted to the cardiovascular intensive care unit, and five days later she was transferred to the ward. The patient developed peroneal nerve damage due to multiple operations which caused weakness in the right foot, ankle, and difficulty in walking. She was, then, referred to our clinic for rehabilitation. When the patient was admitted to our inpatient clinic, she had steppage gait with hyperflexion of the hip and knee joints. The patient also used bilateral crutches. There were scar tissues and suture remained on the anterior face of right thigh, right calf, and medial side of right ankle (Figure 1). During motor examination, the left lower extremity muscle strength was globally $5 / 5$, while the right lower extremity muscle strength was as follows: musculus tibialis anterior $1 / 5$, musculus extensor hallucis longus $1 / 5$, and other muscle groups $5 / 5$. The right ankle range of motion was limited and it had a fixed position of plantar flexion/equinus. During sensory examination, global hyperesthesia was detected in the right leg. The patient complained of pain in the right hip since

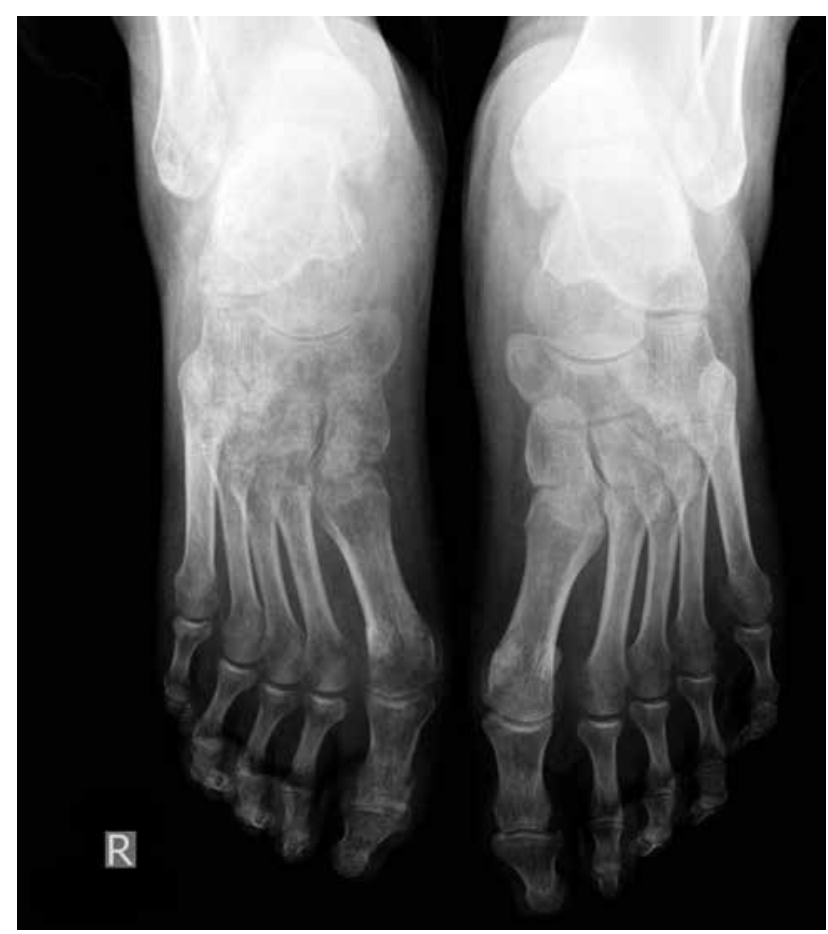

Figure 1. Right lower extremity of the patient. the time of operation. However, no pathology was detected in the right hip range of motion. The patient had a pain score of 5 according to Visual Analog Scale (VAS). Vasomotor and sudomotor trophic changes were observed in the right foot and those changes were attributed to complex regional pain syndrome type II. On plain radiological images, osteoporotic changes in the right hip, narrowing of the right knee tibiofemoral joint space, and patchy osteoporosis in the right foot were observed (Figure 2). Laboratory results showed no sign of pathology, except for HCV positivity. Electromyography revealed right tibial and peroneal nerve axonal damage at the popliteal fossa level.

For limited range of motion of the ankle, stretching and passive range of motion exercises were performed. For pain relief, transcutaneous electrical nerve stimulation device was used for 20 min every day. Electrical stimulation was applied to the right musculus tibialis anterior and musculus extensor hallucis longus. Also, the patient underwent balance and coordination exercises and walking training sessions. The patient had neuropathic pain complaints, for which she received pregabalin $75 \mathrm{mg}$ per day for the first three days and, then, $150 \mathrm{mg}$ per day. The patient also received alendronate $70 \mathrm{mg}$ per week, calcium and vitamin $\mathrm{D}$ supplements as the part of medical treatment.

After medical treatment, the patient reported decreased pain and a pain score of 1 was recorded using the VAS was noted. The right ankle joint range of motion increased and the patient was able to spontaneously bring her foot to the neutral position. However, we observed no improvement in the muscle strength of the right musculus tibialis anterior and musculus extensor hallucis longus. An ankle foot orthosis, which is wearable inside the patient's shoe, was prescribed. An extensive home-based exercise program was also prescribed.

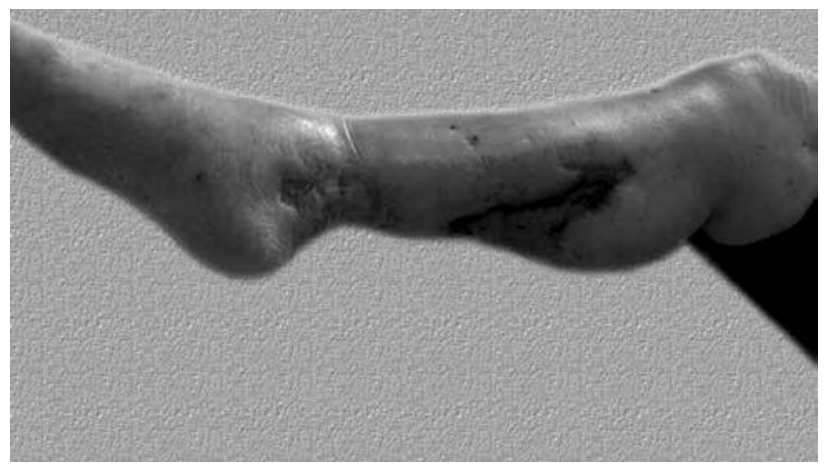

Figure 2. Patchy osteoporosis in right foot. 
At the time of discharge, the patient was able to walk without crutches.

\section{DISCUSSION}

Popliteal artery is the most common site for aneurysms in the lower extremity. Pseudoaneurysms, on the other hand, are rare and usually formed by perforating trauma to the knee. ${ }^{[11]}$ Arterial pseudoaneurysms also occur due to infection, vasculitis, surgical interventions, and IV substance use. ${ }^{[12]}$ Peroneal nerve palsy is a rare complication of popliteal pseudoaneurysms. ${ }^{[13]}$ In our case, our patient had peroneal nerve palsy caused by popliteal artery pseudoaneurysms due to heroin use. Pseudoaneurysms in IV substance users usually occur on the grounds of infection, which is commonly induced by shared injectors. Groin area is usually preferred due to easy application and, therefore, the majority of pseudoaneurysms are located in the femoral artery. Proximity of femoral artery and femoral vein increase the risk of injecting substance in the femoral artery or in its vessel wall by mistake. ${ }^{[7,9,12]}$ There are only a few cases of popliteal artery pseudoaneurysms due to IV drug use reported in the literature. In a retrospective study between 1994 and 1997, complications due to IV drug use were examined. ${ }^{[14]}$ Of 7,795 patients with complications, 11 (0.14\%) had pseudoaneurysms. The most common site for aneurysm was shown to be brachial artery, and only one patient had a popliteal artery aneurysm. In a study by Tan et al., ${ }^{[15]}$ 15 patients who had pseudoaneurysms due to IV substance use were retrospectively analyzed. Of these patients, pseudoaneurysms were found in the femoral artery in 13 patients and in the brachial artery in two patients. Two patients developed critical ischemia postoperatively and underwent bypass grafting surgery two weeks later. Postoperative complications included claudication, digital gangrene, surgical site infection, and hematoma. ${ }^{[15]}$ In our case, pseudoaneurysm and hematoma were treated surgically; however, peroneal nerve damage developed either due to the pressure of hematoma or iatrogenically. Pseudoaneurysm due to heroin use in the popliteal artery is very rare; however, foot drop caused by peroneal nerve damage along with complex regional pain syndrome type II is seen for the first time in the literature. For the complex regional pain syndrome type II diagnosis, pain after nerve damage, allodynia, and hyperalgesia should be present, ${ }^{[16]}$ as in our case. In pseudoaneurysm cases, the initial symptoms are usually pain, swelling, and erythema on the injection site..$^{[9,10,12,15,17]}$ Patients are usually admitted to the emergency clinic with massive bleeding, and patients with pain and swelling, but no bleeding on the injection site should be investigated for pseudoaneurysms and possible drug use. ${ }^{[15]}$ It is recommended to use Doppler ultrasound and computed tomography for the definite diagnosis.

Treatment is usually surgical, and conservative therapy is very rarely used. Unless the lesion recovers, it is prone to life-threatening complications such as rupture, bleeding, and septicemia. Our case was referred to the emergency department with severe bleeding; however, we were unable to collect data on whether she had swelling and pain on the injection site. Our opinion is that the patient probably did not notice those symptoms.

Another complication due to IV substance use is HCV and HIV infections via contaminated injectors. ${ }^{[5-7,18-20]}$ Several studies have shown that 70 to $90 \%$ of substance users are HCV-positive. ${ }^{[18,19]}$ In a study including young individuals who use IV substances in the United States of America, 48\% of the population were tested positive for $\mathrm{HCV}$. Furthermore, this study showed older age, drug abuse for a long period of time, frequent injection use, and sharing the injector with another individual were the main risk factors for HCV infection. ${ }^{[2]}$ In our case, our patient was using IV heroin for over 20 years, and she was tested positive for HCV. The patient also reported that she shared injectors with other individuals from time to time, and she was not very careful with the hygiene of the procedure. In developed countries such as the United States of America, injector exchange programs are carried out to reduce the HCV infection risk among legal or illegal IV substance/drug users. During these programs, injector users are educated and provided with sterile injectors and injector sets. However, the results regarding the overall effects of the program are still insufficient today. ${ }^{[21]}$

The patient had complaints of hip and bilateral knee pain. Complex regional pain syndrome type II at the right foot may explain the presence of pain, although heroin withdrawal symptoms may have contributed. With complex regional pain syndrome type II diagnosis, pregabalin $75 \mathrm{mg}$ bid per day was prescribed and an intensive pain relief was achieved. Pregabalin has been shown to be effective in the treatment of pain as one of heroin withdrawal symptoms; however, when it is used with heroin at the same time, it enhances the effects of heroin and increases the risk of overdose. ${ }^{[22,23]}$ Our patient quitted drug addiction and, therefore, we were able to use pregabalin. We did not encounter any side effects. 
In conclusion, pseudoaneurysms due to IV drug use usually occur in the femoral and brachial arteries. Popliteal artery is a rather rare location. Our case demonstrates a rare complication of IV drug use which caused peroneal nerve palsy leading to foot drop. It should be kept in mind that a swollen, painful area that is prone to bleeding in an IV drug user may be a pseudoaneurysm which can induce axonal nerve damage.

\section{Declaration of conflicting interests}

The authors declared no conflicts of interest with respect to the authorship and/or publication of this article.

\section{Funding}

The authors received no financial support for the research and/or authorship of this article.

\section{REFERENCES}

1. Aceijas C, Stimson GV, Hickman M, Rhodes T Global overview of injecting drug use and HIV infection among injecting drug users. AIDS 2004;18:2295-303.

2. Martins SS, Sarvet A, Santaella-Tenorio J, Saha T, Grant BF, Hasin DS. Changes in US Lifetime Heroin Use and Heroin Use Disorder: Prevalence From the 2001-2002 to 2012-2013 National Epidemiologic Survey on Alcohol and Related Conditions. JAMA Psychiatry 2017;74:445-55.

3. Fareed A, Kim J, Ketchen B, Kwak WJ, Wang D, ShongoHiango $\mathrm{H}$, et al. Effect of heroin use on changes of brain functions as measured by functional magnetic resonance imaging, a systematic review. J Addict Dis 2017;36:105-16.

4. Suzuki J, Valenti ES. Intentional Intra-arterial Injection of Heroin: A Case Report. J Addict Med 2017;11:77-79.

5. Mateu-Gelabert P, Harris S, Berbesi D, Segura Cardona ÁM, Montoya Vélez LP, Mejía Motta IE, et al. Heroin Use and Injection Risk Behaviors in Colombia: Implications for HIV/AIDS Prevention. Subst Use Misuse 2016;51:230-40.

6. Berbesi-Fernández D, Segura-Cardona Á, Montoya-Vélez L, Castaño-Perez GA. Hepatitis C and HIV in injecting drug users in Armenia, Colombia. Adicciones 2015;27:246-52.

7. Novak SP, Kral AH. Comparing injection and non-injection routes of administration for heroin, methamphetamine, and cocaine users in the United States. J Addict Dis 2011;30:248-57.

8. Persiani P, Ranaldi FM, Mazza O, Calistri A, Bove M, Crostelli $\mathrm{M}$, et al. Assessment and therapeutic choice in septic arthritis of the hip in an intravenous drug abuser: case report at 14 years follow-up and review of literature. Clin Ter 2017;168:e8-e13.

9. Coughlin PA, Mavor AI. Arterial consequences of recreational drug use. Eur J Vasc Endovasc Surg 2006;32:389-96.
10. Siu WT, Yau KK, Cheung HY, Law BK, Tang CN, Yang GP, et al. Management of brachial artery pseudoaneurysms secondary to drug abuse. Ann Vasc Surg 2005;19:657-61.

11. Gillespie DL, Cantelmo NL. Traumatic popliteal artery pseudoaneurysms: case report and review of the literature. J Trauma 1991;31:412-5.

12. Fansa İ, Çalışkan K, Altınay L, Güzeloğlu M, Küçüker ŞA. İntravenöz ilaç bağımlılığına bağlı sol femoral psödoanevrizma: Olgu sunumu. Damar Cer Derg 2017;26:66-9.

13. Ersozlu S, Ozulku M, Yildirim E, Tandogan R. Common peroneal nerve palsy from an untreated popliteal pseudoaneurysm after penetrating injury. J Vasc Surg 2007;45:408-10.

14. Tsao JW, Marder SR, Goldstone J, Bloom AI. Presentation, diagnosis, and management of arterial mycotic pseudoaneurysms in injection drug users. Ann Vasc Surg 2002;16:652-62.

15. Tan KK, Chen K, Chia KH, Lee CW, Nalachandran S. Surgical management of infected pseudoaneurysms in intravenous drug abusers: single institution experience and a proposed algorithm. World J Surg 2009;33:1830-5.

16. Harden RN, Bruehl S, Galer BS, Saltz S, Bertram M, Backonja $M$, et al. Complex regional pain syndrome: are the IASP diagnostic criteria valid and sufficiently comprehensive? Pain 1999;83:211-9.

17. Fiddes R, Khattab M, Abu Dakka M, Al-Khaffaf H. Patterns and management of vascular injuries in intravenous drug users: a literature review. Surgeon 2010;8:353-61.

18. Klevens RM, Hu DJ, Jiles R, Holmberg SD. Evolving epidemiology of hepatitis $\mathrm{C}$ virus in the United States. Clin Infect Dis 2012;55 Suppl 1:S3-9.

19. Ly KN, Hughes EM, Jiles RB, Holmberg SD. Rising Mortality Associated With Hepatitis C Virus in the United States, 2003-2013. Clin Infect Dis 2016;62:1287-1288.

20. Eckhardt B, Winkelstein ER, Shu MA, Carden MR, McKnight C, Des Jarlais DC, et al. Risk factors for hepatitis C seropositivity among young people who inject drugs in New York City: Implications for prevention. PLoS One 2017;12:e0177341.

21. Davis SM, Daily S, Kristjansson AL, Kelley GA, Zullig K, Baus A, et al. Needle exchange programs for the prevention of hepatitis $\mathrm{C}$ virus infection in people who inject drugs: a systematic review with meta-analysis. Harm Reduct J 2017;14:25.

22. Lyndon A, Audrey S, Wells C, Burnell ES, Ingle S, Hill R, et al. Risk to heroin users of polydrug use of pregabalin or gabapentin. Addiction 2017;112:1580-1589.

23. Behnam B, Semnani V, Saghafi N, Ghorbani R, Dianak Shori M, Ghooshchian Choobmasjedi S. Gabapentin Effect on Pain Associated with Heroin Withdrawal in Iranian Crack: a Randomized Double-blind Clinical Trial. Iran J Pharm Res 2012;11:979-83. 